\title{
Cerebral Dysplasias as Expressions of Altered Maturational Processes
}

\author{
Harvey B. Sarnat
}

\begin{abstract}
This review identifies the fundamental anatomical and physiological processes that provide the substrates of maturation in the developing nervous system. Cerebral malformations may be viewed from the perspective of aberrations in one or more of these processes. The maturational processes are generally sequential but with considerable temporal precision and overlap: 1) neuronogenesis and gliogenesis, including neural induction by the notochord and primary segmentation of the nervous system; 2) programmed cell death of excess neuroblasts and glioblasts; 3) neuroblast migration; 4) formation and growth of neurites; 5) development of membrane polarity and excitability; 6) synaptogenesis; 7) biosynthesis of neurotransmitters and other secretory products; and 8) myelination of axons. The anatomical and synaptic organization of the fetal brain differs greatly from the mature state. An excess of axonal collaterals, dendritic branches, spines and synapses are formed and later selectively deleted. Transitory neurons, specialized glial cells, synaptic circuits and transient neurotransmitter systems serve as functional elements for a limited time. The clinical expression of these transitory features of the fetal brain are incompletely understood, particularly in the context of embryonic cerebral plasticity.
\end{abstract}

RÉSUMÉ: Les dysplasies cérébrales sont l'expression d'aberrations dans le processus de maturation. Nous présentons une revue des processus anatomiques et physiologiques fondamentaux qui servent de fondement à la maturation du système nerveux en développement. Les malformations cérébrales peuvent être considérées comme des aberrations de l'un ou de plusieurs de ces processus. Les processus de maturation sont généralement séquentiels, avec une précision et un chevauchement considérables dans le temps: 1) la neurogenèse et la gliogenèse, comprenant l'induction neurale par la notocorde et la segmentation primaire du système nerveux; 2) la mort programmée de neuroblastes et de glioblastes en excédent; 3) la migration des neuroblastes; 4) la formation et la croissance des neurites; 5) le développement de la polarité et de l'excitabilité membranaires; 6) la synaptogenèse; 7) la biosynthèse de neuro-transmetteurs et d'autres produits de sécrétion; et 8 ) la myélinisation des axones. L'organisation anatomique et synaptique du cerveau foetal est très différente de celle qui existe à l'état mature. Il se forme un excès de fibres axonales collatérales, de ramifications et d'épines dendritiques, et de synapses, lesquelles sont sélectivement perdues par la suite. Des neurones et des cellules gliales spécialisées, des circuits synaptiques et des systèmes de neuro-transmetteurs, tous transitoires, servent d'éléments fonctionnels pendant une période limitée au cours du développement. L'expression clinique de ces éléments transitoires du cerveau foetal est encore mal comprise, particulièrement dans le contexte de la plasticité cérébrale embryonnaire.

Can. J. Neurol.Sci. 1991; 18: 196-204

Maturation is a composite of growth, a progressive increase in physical parameters such as weight, and development, the acquisition of function, such as the induction of enzyme systems or the beginning of speech and other clinical skills. The anatomical and physiological substrates of maturation in the fetus and infant may be defined as a series of changes leading to specialization of neurons and glial cells to provide more complex functional potential. These changes are sequential, but there is a great deal of temporal overlap so that several processes progress simultaneously. These maturational processes may be summarized as 1) neuronogenesis and gliogenesis including neural induction; 2) programmed cell death of excess neuroblasts and glioblasts; 3) neuroblast migration; 4) formation and growth of neurites (axon and dendrites); 5) development of membrane polarity and excitability; 6) synaptogenesis; 7) synthesis of secretory products; and 8) myelination of axons. Disorders of cerebral growth and development are related to disturbances of one or more of these maturational processes.

\section{Neuronogenesis and Neural Induction}

As the neural tube forms, stratified layers of primitive neuroepithelial cells form the subventricular layer surrounding the central canal and future ventricular system. An ependymal lining is not yet differentiated. The cells at the ventricular wall pro- 
ject a narrow process toward the limiting membrane on the surface of the embryonic spinal cord and brain. The nuclei of these cells shift their position centrifugally within these cytoplasmic processes and then reverse direction and return to the ventricular surface to undergo mitosis. During mitosis, the radial cytoplasmic process is retracted; the two daughter cells then each extend new processes toward the surface of the brain and the process repeats.' The ventricular zone is thus the site of mitotic activity in the early embryonic brain where neuroblasts and glioblasts are generated.

Early neuronal and glial differentiation are closely associated with "induction" of the neural tube by the chordamesoderm. Inductions denotes an influence of one tissue upon another so that the target becomes a tissue that is fundamentally different from the tissue into which the inducer itself differentiates. Induction is usually between different germ layers from the stage of gastrulation, but induction within a germ layer also occurs; the neuroepithelium of the optic cup induces the overlying surface ectoderm to form a lens placode and cornea rather than epidermis. Induction is mediated by peptides and glycoproteins; its specificity is not the inducer but the target receptors that are competent (i.e. receptive) for a specific brief period. Foreign molecules may substitute for the natural inducer and be teratogens to the embryo by causing premature induction. 2.3

Segmentation is mainly a property of mesodermal derivatives, but primary segmentation of the neural tube in the hindbrain region may establish boundaries that prevent the excessive movement of cells between compartments. 4,5 Neural induction may be divided into three phases: formation of the neural placode or the differentiation of neurectoderm from surface ectoderm; neurulation or the formation of the neural tube from the neural placode; and regional differentiation of the ependyma to signal an arrest in mitotic activity of the neuroepithelium. ${ }^{3}$

Disorders of neuronogenesis Factors inhibiting the mitotic proliferation of neuroepithelial cells are difficult to separate from factors which accelerate the process of cell death, but an inadequate rate of genesis of cells within the embryonic nervous system results in severe hypoplasia of the brain and precludes the normal progression of other processes such as neuronal migration, resulting in a brain that is malformed as well as very small; normal synaptic circuits for electrophysiological function cannot develop from the small pool of poorly organized neurons.

Disorders of neurulation almost certainly involve either a functionally defective notochord or an abnormal, unresponsive dorsal ectoderm. Defective chordamesoderm (the notochord and surrounding mesoderm which forms the dermatomes, myotomes and sclerotomes) at the rostral end of the neural tube account for aprosencephaly (atelencephaly; anencephaly). Aprosencephaly has a complex pathogenesis that involves defective cranial growth from abnormal sclerotomes, ${ }^{6}$ failure of notochordal induction of the lamina terminalis to form the forebrain vesicle or prosencephalon, and the encephaloclastic effects of direct exposure of the developing neural tissue to the neurotoxic aminiotic fluid. Holoprosencephaly is probably another disorder of neural induction of the lamina terminalis and of neural structures posterior to the lamina terminalis with a decreasing gradient. The "midline" character of these disorders of neural induction is because all early development of the nervous system occurs in structures that will later be median and paramedian since radial migration has not yet been initiated. Hydranencephaly, by contrast, is not a disorder of neuronogenesis or neural induction but rather a destructive process due to vascular occlusions in the developing fetal brain at a much later stage.

\section{Programmed Cell Death of Excess Neuroblasts and Glioblasts}

A surplus of neuroblasts is produced in all parts of the nervous system, resulting in an excess of 25 to 50 percent of the number needed for mature function. A physiological process ensues in which some cells mature and become permanent and others have only a transient existence and degenerate. This process has been most extensively studied in spinal motor neurons. ${ }^{7-9}$ The mechanism that arrests physiological cell death after the normal complement of remaining cells is achieved is poorly understood.

Many conditions accelerate or delay the process of programmed cell death in experimental animals: electrical stimulation, axotomy, amputation of a limb, grafting of supranumerary limbs, and changes in concentrations of hormones such as thyroid and growth hormone. It is likely that the process of programmed cell death is determined by specific genes that mediate their action by regulating the transcription of RNA and consequently of protein synthesis. The treatment of early chick embryos with inhibitors of RNA and protein synthesis almost completely blocks the massive death of motor neuroblasts induced by amputation of a limb bud. Peripheral targets of axons provide environmental signals or neurotrophic molecules that may override or suppress the expression of a genetically determined developmental fate. ${ }^{10} \mathrm{~A}$ polypeptide purified from skeletal muscle significantly increases the survival of motor neurons during the period of programmed cell death, but does not affect the rate of degeneration of dorsal root ganglion cells. ${ }^{11}$

Disorders of programmed cell death Spinal muscular atrophy (Werdnig-Hoffmann disease) may be an example of a genetic disorder resulting from a failure of the process that stops further physiological cell death of motor neuroblasts after a certain stage of maturity is reached by the nomal fetus. The physiological process becomes pathological by continuing to cause progressive loss of motor neurons in late gestation and postnatally until the muscles become denervated to a degree incompatible with the preservation of life. ${ }^{12}$

Agenesis of the corpus callosum is a common malformation of the brain. In most cases callosal axons do form, but are unable to decussate and are therefore diverted posteriorly along the dorsomedial wall of their hemisphere of origin as the bundle of Probst; it is this large abnormal fascicle that causes the lateral ventricles to be displaced laterally. ${ }^{13}$ In axial images by computed tomography, the forebrain ventricles are not only laterally displaced, but appear as straight parallel structures that have lost the normal convexity toward the midline, and the large bundle of Probst is easily seen interposed between the ventricle and the medial wall of each hemisphere. The callosal plate forms from the dorsal part of the lamina terminalis, the membrane that closes the anterior neuropore and, in the adult brain, forms the anterior wall of the third ventricle. At the time the growth cones of callosal axons approach the callosal plate, a bed of passage is normally created by microcystic degeneration of glial cells that form the callosal plate. If the programmed death of these glial cells does not occur at the precise time, the axons of the corpus 
callosum reach a firm glial obstruction that acts as a brick wall rather than a bridge. They are unable to decussate and are diverted posteriorly to form the bundle of Probst. ${ }^{14}$ Some axons eventually find an alternate route of crossing to the other hemisphere through the anterior commissure and perhaps also the hippocampal commissure, but the details of termination of most fibres of the bundle of Probst remains uncertain. Some cases of colpocephaly are due to complete callosal agenesis, the absence of the posterior fibres causing a loss of white matter and compensatory dilatation of the occipital horns of the lateral ventricles.

Some cases of macrocephaly associated with an anatomically normal-appearing brain by imaging may be due to deficient programmed cell death and a larger than normal complement of surviving neurons and glial cells. An example is Sotos syndrome or cerebral gigantism.

It is unlikely that congenital infections, such as cytomegalovirus disease, accelerate the process of programmed cell death because the virus is unable to enter immature cells that have not yet developed surface receptors to which a foreign substance may attach. The infection perhaps contributes to a loss of mature neurons in already formed structures of the brain, but the extensive lesions in the germinal matrix are due to perfusion failure from vascular involvement. ${ }^{15}$

\section{Neuroblast Migration}

Only rarely do differentiating neuroblasts mature in the human nervous system without shifting position, often to sites quite distant from where they underwent their final mitosis. Neuroblast migration follows predetermined pathways in the brain and is precisely timed in a predictable sequence. Four major pathways of neuroblast migration have been identified in the human brain: 1) migration via the corpus pontobulbare to form brainstem nuclei; 2) migration via the corpus gangliothalamicus to form the thalamus and deep telencephalic nuclei; 3) cerebellar migrations; and 4) radial migration to the cerebral cortex from the periventricular germinal matrix. ${ }^{16}$ Cerebral cortical migrations begin at 6 to 8 gestational weeks and are not completed until 5 months postnatally, though more than half the migration is complete by 16 weeks. The migration of external granular neurons of the cerebellar cortex into the interior of the folia is not completed until a year of age. The brainstem and deep cerebral hemispheric migrations have much shorter cycles and are complete within the first 12 weeks of development. The reason for neuroblast migration is to establish three-dimensional spatial relations between neurons to facilitate the development of synaptic circuits and to arrange neurons in a functional somatotopic sequence. Because of cellular migration, the architecture of the adult brain bears little resemblance to its fetal origin.

In the cerebral cortex, neuroblasts migrate in successive waves toward the developing cortical plate. Upon reaching the pial surface, they reverse direction and pass into deeper layers, displaced by the more recent arrivals. The development of convolutions is directly related to neuroblast migration; it is an efficient manner of increasing the surface area of laminated structures, such as the cerebral and cerebellar cortices without concomitantly increasing the volume of the brain. A similar means of achieving a high surface: mass ratio is found in the intestinal villi, the pulmonary alveoli and the gills of fishes. Too large a brain at birth would be incompatible with survival of the infant, the mother and the species; premature delivery when the head is small is an alternative but also has poor survival value. The sequence and timing of gyration of the human brain are predictable and the gestational age of a preterm infant may be determined from the convolutions of the brain to within two weeks. ${ }^{17}$

Neurons migrate along preformed guides provided by radial glial fibres. Subependymal glial cells of the immature brain have long, radiating processes extending to the pial surface where they terminate as end-feet. The neuroblasts adhere to the outside of these fibre guides and glide toward their destination. ${ }^{16,18}$ The radial processes of these glial cells will later retract and the cells become astrocytes and perhaps other types of glial cells. In the cerebellar cortex, the fibres for guiding external granule neurons are provided by the Bergmann glial cells of the Purkinje cell layer. ${ }^{19}$

Ependymal cells in zones of active neuronal migration develop specialized cytoplasmic proteins that serve as immunohistochemical markers and, more importantly, play a role in the guidance of axonal growth cones and perhaps also in regulating radial glial cells. They disappear after migration is complete. ${ }^{20}$

Disorders of neuroblast migration Nearly all malformations of the brain, small focal dysplasias as well as the major dysgeneses, either result primarily from abnormal neuroblast migration or abnormal migration patterns contribute secondarily to the malformation. Early neuroblast migrational disorders are usually genetically programmed but may be due to congenital infections, metabolic insults, or vascular insufficiency early in gestation that interferes with the function of radial glial fibres or of the neuroblasts themselves. ${ }^{21}$ The result of such disturbances is lissencephaly, pachygyria, and multiple heterotopia or clusters of incompletely migrated nerve cells and glial matrix in the subependymal zone or deep within the white matter.

Late neuroblast migrations are usually not genetic in origin, but rather due to lesions acquired in the perinatal period, either in utero and after delivery. ${ }^{22}$ Structural lesions disrupt the delicate radial glial fibres and cause them to retract from the pial surface. Neuroblasts are able to migrate only as far as their glial guide extends and if they become stranded short of their destination, they mature but are unable to establish their intended synaptic relations with other nerve cells and remain nonfunctional. Such isolated neurons may occur singly or in islands of heterotopic grey matter surrounded by white matter, since lesions often destroy groups of radial glial fibres together. Foci of abnormal cortical lamination due to a late disturbance in neuroblast migration may become epileptogenic because of abnormal synaptic circuitry and unstable membrane excitability. Examples of lesions that generate such focal dysplasias include subependymal haemorrhages, infarcts and cavitation within the subcortical white matter, and superficial lesions of the cerebral cortex such as birth trauma with contusion of the brain, subarachnoid haemorrhage, or neonatal meningitis. Small lesions may be below the limits of resolution of present imaging techniques. Metabolic disturbances in the neonatal period also may interfere with late migrations. Ammonia causes a 40 percent reduction in the amount of glial fibrillary acidic protein (GFAP) in cultured astrocytes. ${ }^{23}$ GFAP forms essential cytoskeletal filaments in radial glial fibres.

Disorders of late neuronal migration occur during a viable period of life, especially in infants born prematurely. They contribute to chronic neurological handicaps: impaired coordination 
and motor disturbances, perceptual difficulties, epilepsy, developmental delay and mental retardation. Improved perinatal care could prevent most disorders of late neuronal migration.

\section{Formation and Growth of Neurites}

The outgrowth of the axon always precedes the development of dendrites, and often begins before neuroblast migration is complete. Axonal connections may form before dendrites even begin to differentiate. The growth of the axon and the projection of its tip to its destination was first recognized by Ramón y Cajal and was named by him the «cône d'accroissement» (growth cone). The trophic factors that guide it to its destination have been debated for nearly a century, but include preformed glial pathways and recently identified special molecules along the pathway such as the highly sialylated neural cell adhesion molecule (N-CAM) and proteoglycans that either attract the growth cone or repel it from places where it should not go.24.25 For example, the roof plate of the spinal ependyma projects fibres dorsally to the surface to serve as a midline barrier. These fibres contain keratan sulfate, a glycosaminoglycan (GAG) that strongly repels growing axons and prevents developing fibres of the dorsal columns of the spinal cord from decussating. ${ }^{24}$

The branching of dendrites eventually accounts for more than 90 percent of the synaptic surface of most mature neurons. The pattern of dendritic arborization is specific for each type of neuron. Spines form upon the dendrites as short protrusions with expanded tips, providing sites of synaptic membrane differentiation.

Disorders of neurite growth Misdirected axons are a common occurrence, ranging from medically trivial cosmetic defects such as the Marcus-Gunn jaw-winking phenomenon in which aberrant trigeminal motor fibres innervate some muscle fibres of the levator palpebrae muscle that causes the patient to "wink" as he chews, to more serious abnormal axonal projections that commonly accompany major malformations of the brain such as holoprosencephaly and lissencephaly. Aberrant decussations of the corticospinal tract or failure to decussate is a particularly common associated anomaly. ${ }^{26}$ At times, aberrant pathways may be beneficial, as in the case of some fibres of the bundle of Probst finding an alternative route across the midline through the anterior commissure in cases of callosal agenesis.

Because so much dendritic differentiation and growth occurs during the last three months of gestation and the first three months of the postnatal period, the preterm infant is particularly vulnerable to noxious influences that adversely affect the maturation of dendrites. Perinatal asphyxia and prematurity may retard dendritic development and spine morphology. ${ }^{27}$ Abnormal dendritic arborization is often the only morphological lesion seen at autopsy in children and adults with undifferentiated mental retardation, and is a likely cause of some idiopathic seizure disorders. Abnormal dendrites are characteristic of chromosomal disease, many genetic diseases such as Menkes' kinky hair disease, cerebro-hepato-renal (Zellweger) syndrome, tuberous sclerosis, and degenerative metabolic diseases of the nervous system such as cerebral lipidoses and leukodystrophies.28-31 Abnormalities include long, thin, tortuous dendritic spines rather than small, stubby spines, absolute decrease in numbers of dendritic spines and synapses, and abnormalities of spatial arrangements of dendrites. In cerebellar hypoplasia, Purkinje cell dendrites show "cactus body" thickenings and loss of branchlet spines. ${ }^{32}$

\section{Development of Neural Membrane Polarity and Excitability}

Reduced to the simplest terms, the neuron may be defined as a secretory cell with an electrically polarized membrane. No other cells of the body possess both characteristics. This definition specifically avoids morphological criteria, such as the development of neurites, and thus is able to encompass chromaffin cells, such as those of the adrenal medulla, and paraneurons, such as those of the carotid body, as neurons despite their lack of axons and dendrites. Membrane polarity is established before synaptogenesis and the synthesis of neurotransmitters develop. The maintenance of a resting membrane potential requires continuous energy expenditure to fuel the sodiumpotassium ATPase system that pumps ions across the cell membrane. The undifferentiated neuroblast is incapable of maintaining such a dynamic condition as a membrane potential, and the various ion channels within the plasma membrane have not yet formed. 33

Disorders of membrane polarity Epileptic phenomena are largely due to inappropriate membrane depolarizations, but are a complex interaction of excitatory and inhibitory synapses that modulate the resting membrane potential. Metabolic and many unknown factors also contribute to the discharge threshold of neural membranes. Hypothalamic and electrolyte disturbances may alter membrane potentials, and the common occurrence of seizures as a complication of many cerebral dysgeneses is probably associated with abnormal resting membrane potentials, perhaps secondary to imbalances of excitatory and inhibitory synapses due to abnormal dendritic development.

\section{Synaptogenesis}

Synapse formation follows the development of dendritic spines. Axonal contact with other nerve cells may precede or follow the completion of neuronal migration. In the cerebellar cortex, external granule cell axons form the parallel fibres of the molecular layer and contact Purkinje cell dendrites before the granule cells migrate to the internal granular layer; ${ }^{34}$ in the cerebral cortex, migrating neuroblasts project long axons caudally, but do not form terminal synapses until after migration is complete. In some cases, cortical neurons may remain dormant in their postmigratory sites for long periods before developing synaptic relations; an example is the olfactory axons in relation to mitral cells of the olfactory bulb. 35

The electroencephalogram in the preterm infant very likely is an indirect composite measure of the degree of synaptogenesis in the cerebral cortex, more than it reflects any other feature of cerebral maturation. Visual evoked potentials and other sensory physiological measures also reflect the maturational state of synaptic organization.

Disorders of synaptogenesis All disorders that result in abnormal dendritic arborization and spine formation necessarily affect synaptogenesis as well. Acquired insults, such as perinatal asphyxia, may cause synapses to become nonfunctional because of depletion and impaired synthesis of transmitter substances. A sudden release of certain excitatory amino acids that normally serve as neurotransmitters, such as glutamic acid, are neurotoxic and cause transsynaptic degeneration of neurons when present in excessive amounts. ${ }^{36}$ 


\section{Biosynthesis of Secretory Products}

The initiation of neurotransmitter biosynthesis is one criterion of neuroblast maturation to become a neuron and is essential for neuronal function. It is accompanied or immediately preceded by the production of large numbers of ribosomes that provides a practical marker of this aspect of neuroblast maturation when tissue sections of infant brain are examined using special stains for nucleic acids such as acridine orange fluorochrome. ${ }^{37}$ RNA is obligatory in the biosynthesis of neuropeptides, and is essential for the assembly of enzymes that have a high rate of turnover, such as those used in the biosynthesis and degradation of acetylcholine and monoamines. Amino acid transmitters do not require RNA for their direct synthesis, and the associated enzyme systems are usually more stable with more reutilization and a slower rate of turnover.

Specialized nerve cells may release their secretory products into the blood rather than at axonal terminals. Chromaffin cells of the adrenal medulla and hypothalamic neurons are examples.

Disorders of neurotransmitter synthesis Ischaemic/hypoxic encephalopathy and many metabolic encephalopathies impair the synthesis of neurotransmitters and cause synaptic failure in the perinatal brain. Inborn errors of metabolism that block the production of essential neurotransmitters such as the monoamines or acetylcholine and hypothetical diseases and are almost certainly incompatible with survival of the fetus. Many genetically-determined diseases of amino acid metabolism are know, and the majority are associated with mental retardation, epilepsy, spastic diplegia and other chronic neurological handicaps. Whether deficiency of the particular amino acid itself or high concentrations of its precursors or of alternative metabolic products is the principal neurotoxic agent is incompletely understand.

\section{Myelination}

The increased conduction velocity of an action potential along an axon provided by myelination is essential to the function of neural systems, because without myelin many axons could not conduct at a fast enough rate to cause depolarization of the next neuron in series and synaptic block would ensue. The myelination of pathways within the central nervous system occurs in a predictable and time-linked sequence. ${ }^{38-40}$ Some tracts, such as the medial longitudinal fasciculus, myelinate as early as 14 weeks and complete their myelination cycle in a few weeks. The auditory pathways including the acoustic nerve, trapezoid body, lateral lemniscus, and brachium of the inferior colliculus, myelinate at about 24 weeks gestation, but the optic nerve does not begin myelination until near-term. The corticospinal tract does not complete its cycle of myelination until 2 years of age. The corpus callosum begins myelination at about 4 months postnatally and completes it in midadolescence. The last pathways to myelinate in the human brain are the ipsilateral frontotemporal association fibres, that are not fully myelinated until about 32 years of age. 38

Myelination sequences in the perinatal period seem to correlate well with the functional development of muscle tone, postures and certain reflexive motor activities. ${ }^{41}$ Descending pathways in the medial part of the brainstem generally become myelinated earlier than those of the lateral part, and corticospinal fibres acquire myelin later still. Our still incomplete understanding of the excitatory and inhibitory influences upon proximal and distal muscle groups of each small tract or physiological groups of tracts provides a basis for proposing an hypothesis of perinatal motor development in accord with the sequence of myelination. ${ }^{41}$ The anatomically small subcorticospinal or bulbospinal pathways, such as the rubrospinal, tectospinal, vestibulospinal, reticulospinal and olivospinal tracts are probably much more functionally important in the neonate than at any later period of life when the corticospinal tract supersedes. Factors other than myelination may be synergistic in the developing nervous system: as corticospinal fibres myelinate, their terminal axonal segments also are developing multiple ramifications that increase the complexity of their synaptic relations within the spinal cord.

Computed tomographic and magnetic resonance imaging provide a practical means of estimating the degree of myelination in major tracts and deep white matter in the living patient.

Disorders of myelination Nutritional deficiencies of the mother or infant, particularly insufficient supplies of fatty acids, may prevent the development of glycolipid and phospholipid compounds that form myelinated membranes, hence delay myelination. Many metabolic diseases, both acquired and genetic, impede the rate of myelination. Examples include hypothyroidism, Menkes' kinky hair disease, cerebro-hepato-renal (Zellweger) disease, and many aminoacidurias. ${ }^{42-44}$ Leukodystrophies, such as Krabbe's disease and metachromatic leukodystrophy, are specific inborn diseases of myelination that are progressive and cause demyelination as well as interfere with new myelin formation. They may already be expressed in the fetus and neonate. Myelination may be used as a parameter reflecting a global delay in brain maturation associated with chronic systemic illness during the first three years of life. ${ }^{45}$

\section{Transitory Features of the Developing Human Brain}

The fetal brain contains many cells which are transitory, serving a function only during a particular stage of development and then disappearing with further maturation. Transitory synapses, dendrites, and neurotransmitters also are well documented, though their functions are often completely unknown.

The fate of some transitory cells of the nervous system is better known than of others. Neuroblasts of the periventricular germinal matrix and of the external granular layer of the cerebellum might be considered "transitory" cells before migration. The surface of the fetal cerebral cortex in midgestation is covered by a subpial granular cell layer, though it is much thinner than the external granular layer of the cerebellum and the cells are much different. The cerebral subpial granular cells are glial rather than neuronal.46,47 They appear to contribute, together with the pial membrane itself, to the formation of a barrier to migrating neuroblasts that reach the surface of the brain and may play a role in reversing the direction of migration of these neuroblasts. In holoprosencephaly, this subpial granular layer of the cerebral cortex is deficient or absent, and over migration is common with extensions of neural tissue and ectopia within the leptomeninges known as "marginal glioneuronal heterotopia".

Another transitory cell of the fetal brain is the Cajal-Retzius neuron. This cell is found in the molecular zone (layer 1) of the fetal cerebral cortex and is present from at least the time of the first wave of neuronal migration and possibly earlier. 48 It projects long axons parallel to the surface of the brain, with collateral extensions into layer 2 of the cortex, where it forms synapses 
with dendrites of pyramidal cells of the future layer 6 that arrive in the earliest waves of neuronal migration. This connection is the first intrinsic synaptic circuit to form in the cerebral cortex. 49,50 The Cajal-Retzius cells disappear during late gestation and are no longer found in mature brain. The function of these transitory cortical neurons is uncertain, but they may provide "pioneer axons" of long descending tracts that help guide axonal growth cones of permanent cortical pyramidal neurons. 51

Just as cells are produced in the central nervous system in overabundance and their number then reduced by programmed cell death, neurites also are often more elaborate at a particular stage of development than later. Axons of the corpus callosum have many more collaterals in the fetal brain than in the adult, and the retraction of axonal collaterals is part of the process of maturation that leaves fewer but more precise connections in a less diffuse distribution. 52 Dendritic trees may be more complex as maturity is approached than after it is achieved. An excessive number of synapses forms on each neuron with subsequent elimination of those not required.53

Basal dendrites of Purkinje cells bear spines and synapses; axosomatic synapses also are common; neither the spines nor the synapses in these positions are found in the adult. The initial axonal segment of motor neurons has synapses in the newborn kitten, but this part of the neuron never has synapses in the adult cat. ${ }^{54}$ The "lamina dessicans" is a transitory layer of cell processes interposed between the Purkinje cell bodies and the internal granular layer of the fetal cerebellum that forms at about 20 weeks gestation and persists for about 10 weeks. It is formed by redundant climbing fibre branches, axonal terminals of climbing and mossy fibres, and transient cytoplasmic growth of developing Purkinje cells.

Neurotransmitter systems are very different in the fetal and adult brain, and many transitory systems occur during development that are absent at maturity. In the fetal cerebellum of 16 to 20 weeks, high concentrations of the neuropeptides somatostatin and substance $P$ are found;55.56 these neuropeptides are in the lowest concentration of any part of the brain in the mature cerebellum. In the cerebral cortex of the frontal lobe, there is a laminar redistribution of cholinergic muscarinic receptors of the mature brain that is the inverse of the pattern shown in the fetus. 57 Tyrosine hydroxylase, a key rate-limiting enzyme in catecholamine synthesis, is present in high concentration in the cerebral cortex of the mouse in the postnatal period, but thereafter decreases rapidly. 58

The neuroanatomical architecture, cell types, fibre connections, synaptic circuits, and pharmacological structure of the fetal brain is more different from the adult brain than the adult human brain differs from other mammalian species. We have only begun to understand the organization of the fetal human brain at various stages of development, and have not yet begun to appreciate the functional clinical expression of these differences and their implications for cerebral plasticity in particular.

\section{Early Embryology of the Human Fetal Nervous System}

Table 1 is a summary of the major maturational events of the human nervous system in the first 74 days of development, and the times of occurrences of the major dysplasias that arise in this period. It is compiled from the work of many authors, but draws

Table 1: Sequence of Normal Embryonic Events in the First $\mathbf{7 4}$ days of Development of the Human Nervous System and Likely Times of Onset of Dysplasias

Age, Length, Somites $\quad$ Normal Developmental Event $\quad-$

\begin{tabular}{ll} 
Age, Length, Somites & Normal Developmental Event \\
\hline 16 days; $0.4 \mathrm{~mm}$ & neural plate \\
18 days; $0.5-1.5 \mathrm{~mm}$ & faint neural groove and early neural folds \\
20 days; $1.5-2.5 \mathrm{~mm} ;$ & $\begin{array}{l}\text { deep neural groove; mesencephalic flexure; prosencephalon, } \\
\text { mesencephalon, rhombencephalon distinguished in neural folds; otic } \\
1-3 \text { pairs somites }\end{array}$ \\
& region detected in rhombencephalic
\end{tabular}

22 days; $2.0-3.5 \mathrm{~mm}$ 4- 12 pairs somites

24 days; $2.5-4.5 \mathrm{~mm}$ 13-20 pairs somites

26 days; $3-5 \mathrm{~mm}$ $21-29$ pairs somites neural groove begins to close, identifying sites of neuropores when embryo possesses 6 pairs of somites; adenohypophysis differentiates; optic primordium and sulcus appear in prosencephalic neural folds; ridge of future optic chiasm (torus opticus) evident; otic plate definite; neural crest emerges from walls of mesencephalic and rhombencephalic neural folds; neural tube shows strong lysosomal enzymatic activity

rostral neuropore closes, cranial vault fully formed; optic vesicle forms optic sulcus; optic neural crest emerges from wall of optic sulcus and vesicle 24-33 days; mamillary recess identifiable; preotic forebrain recognized; primordia of corpus striatum, thalamus, and tegmentum detected; otic pit forms; central canal of spinal cored compressed into vertical shape; entire neural tube shows intense lysosomal enzymatic activity; pia mater derived from neural crest around caudal medulla; definitive notochord present

neurofibrils appear in primary efferent neuroblasts; nasal folds appear near site of rostral neuropore; thinning of roof of rhombencephalon indicates site of future 4th ventricle; additional rostral neural crest emerges from head ectoderm at 26-32 days; vestibulocochlear neural crest emerges from wall of otic vesicle at 26-37 days; rapid development of neural crest in cervical region; closure of caudal neuropore; pia mater develops at mesencephalic level occipital encephalocele

aprosencephaly: extensive spinal dysraphism; pituitary aplasia

meningomyelocele 
Table 1: (Cont'd)

\begin{tabular}{ll}
\hline \hline Age, Length, Somites & Normal Developmental Event \\
\hline 28 days; $4-6 \mathrm{~mm}$ & retinal and lens disks appear; nasal plate defined; alar and basal laminae \\
$30+$ pairs somites & distinguished at midbrain and caudally by sulcus limitans; otic vesicle \\
& closes from surface; endolymphatic appendage distinguished; cervical \\
& flexure appears; occipitospinal nerves and associated ganglia form at 28 \\
& to 32 days; early delimitation of spinal ganglia; wall of neural tube shows \\
& internal segregation of ependymal, mantle, and marginal layers; neural \\
tube site of strong lysosomal enzymatic activity
\end{tabular}

32 days; $5.7 \mathrm{~mm}$

33 days; $7-9 \mathrm{~mm}$

37 days; $8-11 \mathrm{~mm}$

41 days; $11-14 \mathrm{~mm}$

43 days; $12-16 \mathrm{~mm}$

44 days; $13-17 \mathrm{~mm}$

48 days; $16-18 \mathrm{~mm}$

51 days; $18-22 \mathrm{~mm}$

54 days; $23-28 \mathrm{~mm}$ doming of wall of forebrain dorsolaterally indicates cerebral vesicle; hypothalamic sulcus recognized; retinal disk invaginates to form optic cup and retinal (choroid) fissure; neurons of 3 rd and 4th cranial nerves differentiate; fibres of 4 th nerve reach median plane; roots of 5 th to 10 th nerves form; trigeminal ganglion forms 3 short branches; pontine flexure appears; cerebellar plates are lateral recesses of 4th ventricle identified; brachial and lumbosacral plexuses begin to form; blood vessels penetrate wall of brain for the first time, at mesencephalon; prosencephalon surrounded by mesenchyme

prosencephalon cleaves to form paired telencephalon; hypothalamus differentiates; primordium of optic chiasm forms from ventral part of lamina terminalis; pigment appears in external layer of optic cup; nasal pit appears; amygdaloid elevation appears; pineal differentiates in roof of diencephalon; 4th nerves decussate dorsally; motor nucleus and mesencephalic and spinal tracts of 5th nerve and tractus solitarius differentiate; primitive meninx is loose mesenchyme around brain and at mesencephalic flexure is continuous with cellular sheath of notochord

mamillary body forms; subthalamic nucleus and corpus striatum distinguished; evagination of neurohypophysis; fibre tracts form in hypothalamus; primordial hippocampus and adjoining regions differentiate as first cerebral cortical plate; interventricular foramen wide; cellular sheath of notochord participates in formation of medial part of future tentorium cerebelli

mamillothalamic and mamillotegmental tracts appear; subthalamic nucleus further differentiates; internal neuroblastic layer appears in retina; terminalis vomeronasal neural crest emerges from wall of nasal sac and vomeronasal groove at 41-57 days; region of olfactory bulb appears in forebrain; cerebral hemispheres enlarge; hippocampal formation further differentiates; interventricular foramen narrows; first fibres of internal capsule; habenulopedunular tract and posterior commissure form; inferior cerebellar peduncle develops; interhemispheric fissure filled with loose mesenchyme

Cajal-Retzius neurons appear near surface of telencephalon, preceding first wave of migration of subventricular neuroblasts

pharyngeal stalk of adenohypophysis closes; choroid plexuses of lateral ventricles form, ganglion cells of retina give rise to optic nerves; spinal ganglia enter intervertebral foramina; primitive meninx undergoes cavitation, forming a meshwork

neopallium grows rapidly and comprises large part of medial wall of cerebral vescicles; temporal pole appears; choroid plexus of 4th ventricle appears; looser inner and denser outer meninges; major cerebral arteries begin to form; veins representing future dural sinuses lie in outer meninges

chondrocranium well formed; increase in size of all parts of brain; nerve fibre layer appears in retina; optic nerve fibres reach brain; occipital horns of lateral ventricles form; inferior colliculus appears; median aperture of 4 th ventricle (foramen of Magendie) developing but not yet patent

cortical plate of neopallium (future neocortex) appears adjacent to corpus striatum; first interhemispheric commissural fibres from medial pallium into hippocampal and anterior commissures; superior colliculus differentiates; cerebellar plates do not yet reach median plane, but roof plate at that level thickens; median aperture of 4th ventricle opens; dural limiting membrane separating leptomeninges from pachymeninges reaches but does not cover roof of midbrain and hindbrain; dura mater present around spinal ganglia
Dysplasias

retinal coloboma

holoprosencephaly

arhinencephaly

Rathke's pouch and craniopharyngioma

anomalies of major cerebral arteries

colpocephaly

(primary dysplastic form)

Dandy-Walker malformation 
Table 1: (Cont'd)

\begin{tabular}{lll}
\hline \hline Age, Length, Somites & Normal Developmental Event & Dysplasias \\
\hline 55 days; & $\begin{array}{l}\text { central portion of commissural plate undergoes } \\
\text { cystic necrosis and forms thin septal leaves with cavum septi pellucidi } \\
\text { between them }\end{array}$ & septo-optic dysplasia \\
& $\begin{array}{l}\text { earliest growth cones of commissural fibres traverse callosal plate in } \\
\text { dorsal part of lamina terminalis to form corpus callosum; neuroblast } \\
\text { migration into future hippocampus }\end{array}$ & $\begin{array}{l}\text { agenesis of corpus callosum; } \\
\text { beginning period for } \\
\text { disorders of early neuroblast } \\
\text { migration in cerebral cortex } \\
\text { (lissencephaly pachygyria) }\end{array}$ \\
\hline
\end{tabular}

heavily from the many contributions of O'Rahilly, Müller and their colleagues. ${ }^{59,60}$ In linking particular malformations with precise times of development of involved structures, it should be remembered that most teratogenic factors do not act for only a brief time as a single exposure to a drug or toxin, but rather act over a prolonged period and may still be active at birth, as with genetic defects, congenital infections or the continued exposure to toxic substances.

\section{REFERENCES}

1. Sauer FC, Mitosis in the neural tube. J Comp Neurol 1935; 62: 377-405.

2. Duprat AM, Gualandris L, Kan P, et al. Review: Neural induction. Arch d'Anat Microsc Morphol Exp 1987; 75: 211-227.

3. Sarnat HB. Cerebral Dysgenesis. Embryology and Clinical Expression. New York: Oxford University Press, 1992: in press.

4. Keynes RJ, Lumsden A. Segmentation and the origin of regional diversity in the vertebrate central nervous system. Neuron 1990; 2: $1-9$.

5. Trevarrow B, Marks DL, Kimmel CB. Organization of hindbrain segments in the zebrafish embryo. Neuron 1990; 4: 669-679.

6. Marin-Padilla M. Embryology and pathology of axial skeletal and neural dysraphic disorders. Can J Neurol Sci 1990; 17: 153-169.

7. Hamburger V, Levi-Montalcini R. Proliferation, differentiation, and degeneration in the spinal ganglia of the chick embryo under normal and experimental conditions. J Exp Zool 1949; 111 : 457 502.

8. Nurcombe V, McGrath PA, Bennett MR. Postnatal death of motor neurons during the development of the brachial spinal cord of the rat. Neurosci Lett 1981:27:249-254.

9. Okada N, Oppenheim RW. Cell death of motoneurons in the chick embryo spinal cord. J Neurosci 1984; 4: 1639-1652.

10. Oppenheim RW, Prevette D, Tytell M, et at. Naturally occurring and induced neuronal death in the chick embryo in vivo requires protein and RNA synthesis: Evidence for the role of cell death genes. Dev Biol 1990; 138: 104-113.

11. McManaman JL, Oppenheim RW, Prevette D, et al. Rescue of motoneurons from cell death by a purified skeletal muscle polypeptide: Effects of the ChAT development factor, CDF. Neuron 1990; 4: 891-898.

12. Sarnat HB, Jacob P, Jiménez C. Atrophie spinale musculaire: L'évanouissement de la fluorescence à l'A.R.N. des neurones moteurs en dégénérescence: une étude à l'acridine-orange. Rev Neurol (Paris) 1989; 145: 305-311.

13. Rakic P, Yakovlev PI. Development of the corpus callosum and cavum septi in man. J Comp Neurol 1968; 132: 45-72.

14. Zaki $W$. Le processus dégénératif au cours du développement du corps calleux. Arch Anat Micr Morphol Expér 1985; 74: 133-149.

15. Marques MJ, Harmant-van Rijckevorsel G, Landrieu P, et al. Prenatal cytomegalovirus disease and cerebral microgyria:
Evidence for perfusion failure, not disturbance of histogenesis, as the major cause of fetal cytomegalovirus encephalopathy. Neuropediatrics 1984; 15: 18-24.

16. Sidman RL, Rakic P. Neuronal migration, with special reference to developing human brain: A review. Brain Res 1973; 62: 1-35.

17. Chi JG, Dooling EC, Gilles FH. Gyral development of the human brain. Ann Neurol 1977; 1: 86-93.

18. Choi BH. Glial fibrillary acidic protein in radial glia of early human fetal cerebrum: A light and electron microscopic immunoperoxidase study. J Neuropathol Exp Neurol 1986; 45: 408-418.

19. Choi BH, Lapham LW. Evolution of Bergmann glia in developing human fetal cerebellum: A Golgi, electron microscopic and immunofluorescent study. Brain Res 1990; 190: 369-383.

20. Sarnat HB. Regional differentiation of the human fetal ependyma: Immunocytochemical markers. J Neuropathol Exp Neurol 1991; 50: in press.

21. Barth PG. Disorders of neuronal migration. Can J Neurol Sci 1987; 14: 1-16.

22. Sarnat HB. Disturbances of late neuronal migrations in the perinatal period. Am J Dis Child 1987; 141: 969-980.

23. Norenberg MD, Neary JT, Norenberg L-OB. Ammonia induced decrease in glial fibrillary acidic protein in cultured astrocytes. J Neuropathol Exp Neurol 1990; 49: 339-405.

24. Snow DM, Steindler DA, Silver J. Molecular and cellular characterization of the glial roof plate of the spinal cord and optic tectum: A possible role for a proteoglycan in the development of an axon barrier. Dev Biol 1990; 138: 359-376.

25. Letourneau PC, Shattuck TA, Roche FK, et al. Nerve growth cone migration onto Schwann cells involves the calcium-dependent adhesion molecule, $\mathrm{N}$-cadherin. Dev Biol 1990; 138: 430-442.

26. Roessmann U, Hori A. Agyria (lissencephaly) with anomalous pyramidal crossing. J Neurol Sci 1985; 69: 357-364.

27. Takashima S, Chan F, Becker LE, et al. Morphology of the developing visual cortex of the human infant. A quantitative and qualitative Golgi study. J Neuropathol Exp Neurol 1980; 39: 487-501.

28. Marin-Padilla M. Abnormal neuronal differentiation (functional maturation) in mental retardation. Birth Defects 1975; 11: 133-153.

29. Suetsugu M, Mehraein P. Spine distribution among the apical dendrites of the pyramidal neurons in Down's syndrome. A quantitative Golgi study. Acta Neuropathol 1980; 50: 207-210.

30. Becker LE, Takashima S. Dendritic structure in the leucodystrophies: A Golgi analysis of metachromatic leucodystrophy, adrenoleucodystrophy, Cockayne's disease, and PelizaeusMerzbacher disease. Int symp on the leucodystrophies and allied diseases. Kyoto, Japan, 19-20 Sept 1981: 37-52.

31. Becker LE. Synaptic dysgenesis. Can J Neurol Sci 1990; 17: 170180.

32. Sarnat HB, Alcalá $\mathbf{H}$. Human cerebellar hypoplasia: A syndrome of diverse causes. Arch Neurol 1980; 37: 300-305.

33. Spitzer N. Development of membrane properties in vertebrates. Tends Neurosci 1981; 4: 169-172. 
34. West MJ, Del Cerro M. Early formation of synapses in the molecuIar layer of the fetal rat cerebellum. J Comp Neurol 1975; 165: 137-160.

35. Hinds JW, Hinds PL. Synapse formation in the mouse olfactory bulb. I. Quantitative studies. J Comp Neurol 1976; 169: 15-40.

36. McDonald JW, Johnston MV. Physiological and pathophysiological roles of excitatory amino acids during central nervous system development. Brain Res Rev 1990; 15: 41-70.

37. Sarnat HB. Répartition de l'A.R.N. au cours de la migration neuronale dans les cerveaux normaux et dysplastiques en développement chez l'homme: Étude à l'acridine-orange. Rev Neurol (Paris) 1989; 145: 127-133.

38. Yakovlev PI, Lecours A-R. The myelination cycles of regional maturation of the brain. In: Minkowski A, ed. Regional Development of the Brain in Early Life. Philadelphia: FA Davis, 1967: 3-70.

39. Gilles FH. Myelination in the human brain. Hum Pathol 1976; 7 : 244-248.

40. Brody BA, Kinney HC, Kloman AS, et al. Sequence of central nervous system myelination in human infancy. I. An autopsy study of myelination. J Neuropathol Exp Neurol 1987; 46: 283-301.

41. Sarnat HB. Do the corticospinal and corticobulbar tracts mediate functions in the human newborn? Can J Neurol Sci 1989; 16: 157-160.

42. Ghatak NR, Hirano A, Poon TP, et al. Trichopoliodystrophy. II. Pathological changes in skeletal muscle and nervous system. Arch Neurol 1972; 26: 60-72.

43. Volpe JJ, Adams RD. Cerebro-hepato-renal syndrome of Zellweger: An inherited disorder of neuronal migration. Acta Neuropathol 1972; 20: 175-198.

44. Balázs RB, Brooksbank WL, Davison AN, et al. The effect of neonatal thyroidectomy on myelination in the rat brain. Brain Res 1969; 15-219-232.

45. Dambska M, Laure-Kamionowska M. Myelination as a parameter of normal and retarded brain maturation. Brain Dev (Tokyo) 1990; 12: 214-220.

46. Brun A. The subpial granular layer of the foetal cerebral cortex in man. Its ontogeny and significance in cortical malformations. Acta Pathol Microbiol Scand 1965; suppl 179.

47. Sanides F, Sas E. Persistence of horizontal cells of the Cajal foetal type and of the subpial granular layer in parts of the mammalian paleocortex. Z mikr-anat Forschung 1970; 82: 570-588.
48. Duckett S, Pearce AGE. The cells of Cajal-Retzius in the developing human brain. J Anat 1968; 102: 183-187.

49. Molliver ME, Kostović I, Van der Loos H. The development of synapses in cerebral cortex of the human fetus. Brain Res 1973; 50: 403-407.

50. Marín-Padilla M. Structural organization of the human cerebral cortex prior to the appearance of the cortical plate. Anat Embryol 1983; 168: 21-40.

51. McConnell SK, Ghosh A, Shatz CJ. Subplate neurons pioneer the first axon pathway from the cerebral cortex. Science 1990; 245: 978-982.

52. Gravel C, Hawkes R. Maturation of the corpus callosum of the rat: I. Influence of thyroid hormones on the topography of callosal projections. J Comp Neurol 1990; 291: 128-146.

53. Purves D, Lichtman JW. Elimination of synapses in the developing nervous system. Science 1980; 210: 153-157.

54. Ronnevi L-O, Conradi S. Ultrastructural evidence for spontaneous elimination of synaptic terminals on spinal motoneurons in the kitten. Brain Res 1974; 80: 335-359.

55. Inagaki, S, Sakanaka $S$, Shiosaka $S$, et al. Experimental and immunohistochemical studies on the cerebellar substance $P$ of the rat: Localization, postnatal ontogeny, and ways of entry into the cerebellum. Neuroscience 1982; 7: 639-646.

56. Inagaki S, Shiosaka S, Takatsuki K, et al. Ontogeny of somatostatin-containing neuron system of the rat cerebellum including its fibre connections: An experimental and immunohistochemical analysis. Dev Brain Res 1982; 3: 509-529.

57. Johnston MV, Silverstein FS, Reindel FO, et al. Muscarinic cholinergic receptors in human infant forebrain: $\left[{ }^{3} \mathrm{H}\right]$ quinuclidinyl benzilate binding in homogenates and quantitative autoradiography in sections. Dev Brain Res 1985; 19: 195-203.

58. Satoh J, Suzuki K. Tyrosine hydroxylase-immunoreactive neurons in the mouse cerebral cortex during the postnatal period. Dev Brain Res 1990; 53: 1-5.

59. O'Rahilly R, Gardner E. The timing and sequence of events in the development of the human nervous system during the embryonic time period proper. Z Anat Entwickl-Gesch 1971; 134: 1-12.

60. Müller F, O'Rahilly R. The human brain at stages $21-23$, with particular reference to the cerebral cortical plate and to the development of the cerebellum. Anat Embryol 1990; 182: 375-400. 